\begin{tabular}{|c|c|}
\hline & $\begin{array}{l}\text { International Journal of Trend in Scientific } \\
\text { Research and Development (IJTSRD) }\end{array}$ \\
\hline 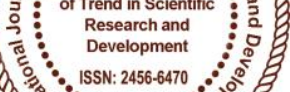 & International Open Access Journal \\
\hline 00000 & ISSN No: $2456-6470 \mid$ www.ijtsrd.com | Volume - 2 | Issue - 1 \\
\hline
\end{tabular}

\title{
Vibration Analysis on Car Seats due to Rough and Smooth Road Conditions
}

\author{
L. Chandra Sekhar \\ $4^{\text {th }}$ Year Student, Department of \\ Mechanical Engineering, Saveetha \\ School of Engineering, Saveetha \\ University, Chennai. India
}

\author{
V.Ram Abhishek \\ $4^{\text {th }}$ Year Student, Department of \\ Mechanical Engineering, Saveetha \\ School of Engineering, Saveetha \\ University, Chennai. India
}

\author{
D.Upendra Reddy \\ $4^{\text {th }}$ Year Student, Department of \\ Mechanical Engineering, Saveetha \\ School of Engineering, Saveetha \\ University, Chennai. India
}

\begin{abstract}
By and large four wheeler vehicles are one of the well known vehicles in city transport. Four wheeler vehicles are presented to vibrations because of unpredictable surface of streets. This influences the well being and in addition inconvenience of the driver and travelers. The motions are moved into the group of driver and traveler through the body tissues, organs and frameworks of the individual causing different impacts on the structures inside the body before it is hosed and scattered. From writing review uncovers that vibrations are most dangerous to the wellbeing in the event that it surpasses the cutoff. In the present work the test examination is completed. To quantify the extent of the vibrations following up on driver and in addition traveler for the distinctive street profile at various speed.
\end{abstract}

\section{INTRODUCTION}

The examination of excitation and vehicle body developments following up on the two front wheel of the vehicle because of the street profile and driving moves in view of the trials on two vehicles.

\section{GENERAL INTRODUCTION}

Autos are for the most part utilized for the agreeable voyage. The plan and testing of an auto is critical to the point that they ought to guarantee both well being and solace. The outline and manufacture of an auto is by and large isolated into eight sub framework plan. They are
a) Body and edge
b) Wheels and Tires
c) Engine
d) Transmission
e) Suspension framework
f) Steering framework
g) Braking framework
h) Ergonomics

Subsequent to planning an auto many tests are done on it before discharging it into the market. Additionally the tests are done on the vehicles at different phases of assembling, creating and utilizing. The basic tests on any vehicle are done to guarantee that the wellbeing of the vehicle. Tests are done on each above expressed framework and checked for tasteful working. However there are many tests are done to check the solace levels of the vehicle. Presently a-days it is most imperative to guarantee that diverse vibrations and clamor display in the vehicle must be controlled. For this NVH testing is done on various parts of a vehicle.

\section{NVH TESTING}

NVH (clamor, vibration and brutality) execution straightforwardly influences a client's view of vehicles. It specifically impacts vehicle's business, sturdiness, guarantee expenses and client driving solace. A decent vehicle NVH configuration needs to begin from a well idea NVH improvement process, and to take after framework designing standards. It needs to adjust a wide range of traits, for example, 
vehicle elements, vehicle mark picture, vehicle advertise position, target client gatherings. It should be outlined in light of the above parameters, in addition to having a NVH additionally save to ensure the vehicle still meets its building targets when it is conveyed to advertise. Building contemplations on target falling, partition of basic modes, detachment of various sound and vibration transmission ways, vehicle equipment outline standards for $\mathrm{NVH}$, lastly $\mathrm{NVH}$ vehicle level conveyances are all of awesome enthusiasm to car businesses.

NVH (Noise, Vibration and Harshness) is a standout amongst the most critical pointers of riding solace. With the fast advancement and furious rivalry of the car business, client's necessity on NVH is expanding. Directing wheel vibrations genuinely influence $\mathrm{NVH}$ execution, as well as have negative effect on the steadiness and security. Control of the controlling wheel vibrations is basic to enhance vehicle execution.

Seating flow, particularly the human view of the dynamic solace of a seat, is a range that is of expanding significance to car.

Makers providing food for a market winding up increasingly aggressive and complex. A noteworthy segment of the vibration experienced by the inhabitants of a car enters the body through the seat. To date huge consideration has been paid to the static solace of seats while chip away at dynamic seat comfort is limited. In India autos are one among the significant vehicles utilized by individuals for transportation. Aside from contamination and execution, economy, wellbeing and solace are main considerations to consider. Solace of the driver assumes an imperative part in the traveler security, weakness amid lengthy drive, and drivability in substantial movement. Solace implies nonattendance of any discomfort[1]. An auto driver frequently drives the vehicle through a wide range of street conditions. While considering the solace, the seat is one of the primary segments, which has guide contact to the driver. Seat offers help to the driver, to such an extent that the weight appropriation of the seat ought to be uniform wherever on the seat. Seat must keep away from the vibration transmitted from the street surfaces and power prepare, so as to maintain a strategic distance from back turmoil, deftness, vision disability and so on. Likewise the delayed introduction to vibration makes weariness the traveler. So to stay away from this vibration we require a vibration isolator - situate. Seat ought to strongly fill its proposed need for its lifetime. To evaluate the vibration disengagement productivity of the seat the term Seat Transmissibility is utilized. It is the proportion of vibration at the highest point of the seat to the vibration at the edge.

Transmissibility $=$ vibration of seat $/$ vibration at the frame

The transmissibility of the seat will disclose to us the conduct of the seat at various street condition with various recurrence inputs. Transmissibility shifts as recurrence changes.

The work is an endeavor towards concentrate dynamic attributes of traveler situate for comfort through target assessment [3]. For target assessment, the transmissibility and ride comfort Index were found under two distinct conditions on four unique autos. For better understanding the vibration transmissibility key focuses taken for examination are: 1. Transmissibility esteems at various conditions 2. Solace file according to ISO 2631 for various conditions.

\section{SEAT EFFECTIVE AMPLITUDE TEST SEAT}

Trial examination is completed on driver seat to assess picks up, situate powerful adequacy transmissibility, and is an endeavor to comprehend seating frameworks damping attributes under constant conditions. A mass heap of $60 \mathrm{~kg}$ is utilized amid the test. The vehicle was tried in two street landscapes, harsh and smooth. The instrumentation and setup utilized for the analysis is as per the following,

Position 1 - Seat base

Position 2 - Seat mount

1. Vehicle under examination

2. Accelerometers 2 No's

3. Data Acquisition Unit

\section{Post processor}

5. Rigid sham (60 $\mathrm{kg}$ - proportionate to seating weight)

Information was gotten from the accelerometer introduced at the seat mounts, though yield information would be acquired from the seat cushion accelerometer put on the seat base. The increasing 
speed comes about are recorded according to various trial conditions. The test was done on situate with sham stacked on it. Yield diagrams regarding increasing velocities versus (time area yield), increasing speeds versus (recurrence space yield), and transmissibility versus recurrence are plotted.

\section{TRANSFER PATH OF VIBRATIONS TO THE STEERING WHEEL}

The fundamental excitation sources are ordinarily motor and street unpleasantness in may traveler autos. Sometimes there are vibrations because of some extra parts like cooling fans and so forth. Motor is the fundamental driver of vibration of vehicle in the stationary condition. But while moving the street unevenness causes to some degree high abundance vibrations and these vibrations are even enhanced by the speed of the vehicle. From the excitation sources the vibrations exchange through various ways to directing wheel, the ways are as appeared in the Figure. In the traveler autos advancing into the market it is important to ensure that there is no such guiding play and furthermore if any of controlling play exists it can be distinguished with no hardware. So it is quite required to focus on the staying two headings.

\section{VIBRATION MEASUREMENT SENSORS}

Many types of detector is used for this purpose. The foremost usually used ones area unit electricity sensors and IEPE sensors (with integrated signal conditioning). There area unit alternative brands for low frequencies (like piezo-resistive, electrical phenomenon or MEMS sensors) and non-contact probes (eddy current probes and optical device sensors).

\section{PIEZOELECTRIC SENSORS}

Piezoelectric sensors chip away at the rule that a piezoelectric material is worked between the base of the sensor lodging and the seismic mass. At the point when a sensor is moved, this mass packs the piezoelectric material which delivers little voltages. To exchange those little electrical esteems through the links require bunches of learning and costly cabling, in this way recently these sensors have regularly been supplanted with the IEPE sensors with coordinated speakers. Be that as it may, there are still applications regions where these sensors are exceptionally helpful. These fields are particularly high increasing speed and high temperatures. The sufficiency estimation scope of such sensors can be a great. One can discover single hub and tri hub sensors.

\section{PROBLEM STATEMENT}

By and large, car outline and the body can be bolstered by suspension. Other than that the suspension system is enabling the wheels to "splash up" wrong-doing out and about surface. The result is the wheels will tend to remain in contact with the street, and the travelers of the vehicle appreciate a ride that is shielded from street stun.

The front suspension need to concentrate on help the heaviness of the front end of the vehicle, ingest street stuns and pad the travelers and load against those stuns, give directing control and arrangement and keep up controlling control amid extreme braking. Notionally, if a street were impeccably level, with no variation from the norm, suspensions wouldn't be vital. Tragically, streets are a long way from level. Without suspension, an engine vehicle going at today speeds would not exclusively be awkward, it would be practically wild. Guiding wheel vibrations are seen when vehicle speed changes, as when beginning from a quit, passing, and backing off or drifting. The view of ride quality is debased by for all intents and purposes any aggravation experienced by the drivers or travelers. Human affectability differs as per the idea of the unsettling influence. In this way, a great Ride not simply relies upon the general plan of the vehicle, yet additionally the outline of the suspension framework. Indeed, even naturally cleared roadways have downplayed blemishes that can connect with the wheels of an auto.

Rather than convey the heap from motor compartment, distinctive street condition will gives diverse results for the front suspension framework. The front suspension framework was assigned to perform at certain scope of vibration. However the drivers and travelers, sure of them not just utilized the vehicle on the smooth street yet then on the different sort of street which here and there the front suspension does not perform on that sort of street. In this way, the venture will research the seat checking of controlling wheel vibrations on traveler auto.

\section{ACCELEROMETER}

Accelerometer is a Piezo-electric accelerometer and it is considered as the standard vibration transducer for machine vibration estimation. Information catch in regards to the vibration radiated by a machine, or 
other body, starts with the sensor. The accelerometers appeared in Fig comprise of a piezoelectric gem which has a mass joined to one of its surfaces. At the point when the mass is subjected to a vibration flag, the mass changes over the vibration (speeding up) to a constrain, this at that point being changed over to an electrical flag. This is the premise of the "accelerometer". The accelerometer yield may then be handled to give the momentary vibration and dislodging signals.
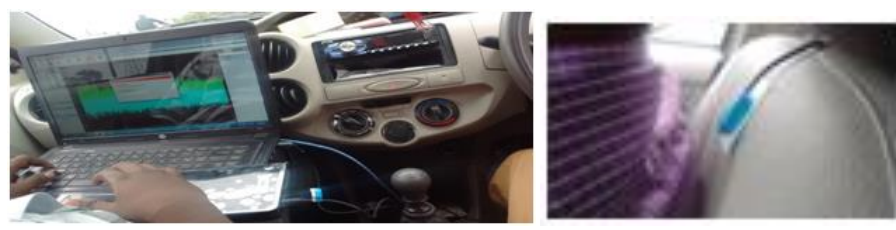

Fig2: Testing of Accelerometer Sensor

Low Impedance Artistic Shear accelerometers outlined like the quartz-based K-SHEAR line. Tough, hermetic, lightweight with low affectability to base strain, warm homeless people and transverse increasing velocities. These units are perfect for single to multi-channel modular.

\section{CONCLUSION}

In the flat heading the vibration variety in seats wheel for Tata Indica is more than Toyota Etios at various paces. With the end goal that it can be thought as the two vehicles have almost same physical measurements and same suspension so the vibrations in the vertical bearing are same.

The opposition in the market is regularly expanding and the requirement for improvement of items is fundamental. In the field of autos particularly in autos the most essential component is comfort. So the NVH testing is imperative. The two fundamental zones of driver comfort are directing and situate. So the testing and benchmarking the directing wheel vibrations is essential.

\section{REFERENCE}

1) Shahram Azadi, Mohammad Azadi and Farshad Zahedi, "NVH analysis and improvement of vehicle body structure using DAE method", Journal of Mechanical Science and Technology, pp. 1980-1989.

2) Siddha Uttam Y. and kumbhar Samir B.,"Natural frequency analysis of automobile seating system by using FEM software",
International Journal on Mechanical Engineering and Robotics, vol. 1, pp. 93-98, 2013.

3) Uday M. jamdade, Sandip H. Deshpande and Sanjay S. Deshpande, "Modal analysis of automobile seating system", IPASI International Journal of Mechanical Engineering, vol. 2, pp. 4148, 2014.

4) Wael Abbas, Ashraf Emam, Saeed Badran, Mohamed Shebl and Ossama Aboueletta,"Optimal seat and suspension design for a half car with driver model using genetic algorithm", Intelligent Control and Automation, pp 199-205, 2013.

5) Fransis Augustine Joseph, Dr. Jason Cherian Issac and T. J. Paulson, "Low frequency vibration analysis on passenger car seats", International Journal of Scientific and Engineering Research, vol. 4, pp. 77-81, 2013.

6) Dr. Jason C. Issac, Prof. T. J. Paulson, "Low Frequency Vibration Analysis on Passenger Car Seat," International Journal of Scientific and Engineering Research; vol. 4, pp. 229-235, 2013.

7) Lee, J.H.; and Singh, R. (2008). Nonlinear frequency responses of quarter vehicle models with amplitude-sensitive engine mounts. Journal of Sound and Vibration, 313(3-5), 784-805.

8) Maeda, S.; Mansfield, N.J.; and Shibata, N. (2008). Evaluation of subjective responses to whole-body vibration exposure: Effect of frequency content. International Journal of Industrial Ergonomics, 38(5-6), 509-515.

9) Amman, S.; Pielemeier, W.; Meier, R.; Bergeon, S.; Shiau, N.M.; and Gorodisher, A. (2003). Subjective and objective quantification of steadystate idle vibration felt through the seat. SAE Paper 2003-01-1512.

10) Hosseini Fouladi, M.; Mohd. Nor, M.J.; Ariffin, A.K. (2009). Spectral analysis methods for vehicle interior vibro-acoustics identification. Mechanical Systems and Signal Processing, 23(2), 489-500. 